\title{
Editorial
}

\section{Resilience among people who face natural disaster}

\section{De Sousa $\mathbf{A}^{1}$, Shrivastava $\mathbf{A}^{2}$}

1. Consultant Psychiatrist - Desousa Foundation and Senior Research Associate, department of Psychiatry, Lokmanya Tilak Municipal Medical College, Mumbai

2. Associate Professor of Psychiatry, Associate Scientist, Lawson Health Research Institute and Physician, Regional Mental Health Care, The Western University, Canada.

Email *Corresponding Author: avinashdes888@gmail.com

Human beings possess the power to resist an adverse situation and this unique characteristic is one of the basic instinct to survive. Individual capacity to deal with insurmountable adversities is a matter of great astonishment. Often physical capacity fails but drive and conviction to survive in difficult situations persist and remains source of strength. In language of understanding it is referred to an internal capacity to fight. A number of people refer to this as 'resilience'. There are about seventy definitions of the term resilience. The Oxford dictionary defines it as 'the capacity to recover quickly from difficulties and toughness'. ${ }^{1}$ Considering most of the references to tern resilience it appears to be 'human capacity to deal with adverse situations and quickly bounce back to normalcy'.

We believe that resilience is a psychobiological construct which explains most of its features. ${ }^{2}$ It has 4 basic components viz. adaptation, optimism, satisfaction and contentment. Resilience remains responsible for all these four components of human experience. It is not only the capacity to deal with difficult situations in an 'elastic' manner and 'bounce back to normalcy' but it goes far beyond this process, it allows a person to peruse and retain the capacity to think, to plan, and to judge. Thus resilience also determines how not to loose characteristics which constructs other basic emotions, thought, memory and insight.

The psychology and neurobiology of trauma has been studied extensively and volumes have been written on the subject. Resilience has always been a subject of research in response to stress and trauma while research on the baseline resilience in human subjects and resilience in the wake of health and disease has been understudied. ${ }^{3}$ The scientific study of resilience is enormously vexing and complex. When studying the response of human beings and their resilience to trauma it is paramount to have a valid and acceptable definition of resilience. While a number of reviews have been written on the conceptual elaboration of resilience, a clear and concise definition is often muddled and fuzzy. ${ }^{4}$ Many themes have been encompassed under the rubric of resilience, partly confounded by the situation or study population in whom resilience is defined. Resilience may be defined by some as the ability to bounce back positively from adversity ${ }^{5}$, while others feel it is the ability to remain symptom free from a psychological standpoint in the wake of trauma and stress. ${ }^{6}$ There are also neurobiological connotations to resilience that delineate it to entailing a superior biological response to stress. Resilience is in fact not merely biological but rather a psychobiological construct that plays a role in the response, recovery and long term adaptation to trauma. $^{7}$

Resilience in response to natural disasters would be defined as an ability to bounce back and return to normal despite the plight and destruction as an aftermath of disaster. Resilience following natural disaster occurs at multiple levels. It involves the individual, the family, the community and the nation or city at large. Resilience when measured serves as a marker of recovery from trauma and implicates prognosis. Unlike individual traumatic events natural 
disasters have the propensity to act on the individual, the family and the community all together and at the same time. ${ }^{8}$ The resilience in response to disaster is influenced by a number of factors. This depends on whether the individual had a direct exposure with a threat of death or had an indirect exposure to the disaster. Proximity, location of resources and type of infrastructure available after a disaster plays an important role in the development and maintenance of resilience. The presence of physical trauma like loss of a limb, head injury and other medical conditions that worsen due to the disaster may influence resilience as well. The psychological sequel of disasters is widespread, long lasting and far more influential on resilience than the physical aspects. Grief whether personal and community plays an important role in the individual bouncing back to normalcy. Death of a close family member also influences the development of resilience while this is further complicated when all the family members of an individual are wiped out and survivor guilt sets in. The trajectory of psychiatric illness following disasters is variable and lasts for years and months after the trauma. The speed at which rescue operations are initiated and started also determine resilience both in an individual as well as the community. Loss of shelter, loss of livelihood, lack of food and water, financial losses and displacement from place of residence also affect resilience and its development. Another important determinant of resilience is the bonding and togetherness between the community members affected by disaster. This togetherness if present builds community resilience and enhances recovery thereby further fostering individual resilience. Sometimes disasters may have economic and political implications for a nation and change its economy in a massive way. This though indirectly may affect recovery of communities and individuals from trauma. ${ }^{9}$

Resilience has been studied in response of human subjects to natural disasters like floods, tsunamis and earthquakes. Resilience in response to natural disasters is multidimensional and transactional in nature. The multidimensional aspect emphasizes the role of multiple factors viz. biology, psychology, social support, genetics and endurance in the development of resilience. The transactional nature defines resilience as a dynamic process in mans response to the changes in the environment around him as in the case of natural disasters. ${ }^{10}$ Resilience in response to natural disasters is also enduring in nature and determined by the baseline resilience of the population in question. A number of salutogenic factors like positive mindset, family support, social ties, community support, pre-disaster lifestyle and the absence of premorbid psychopathology play a role in determining resilience as a response. It is also noteworthy to mention that resilience may differ geographically as some parts of the world are more prone to natural disasters from an ecological perspective. This may lead to an inbuilt resilience in many such prone populations who may handle disaster better than if the disaster occurred in populations which were unprepared or unable to fathom the magnitude of the disaster. This brings in a transcultural aspect to resilience when one compares the occurrence of natural calamities in Asia versus the west and is a subject worth investigating. ${ }^{10}$

One of our studies conducted in the aftermath of the floods and mass devastation in Uttarakhand in Nothern India revealed that social support was a key determinant in resilience amongst those who lost a close family member in the tragedy. We studied resilience amongst those that had lost a close family member and found that keeping all factors the same it is the amount of social support, basic needs fulfillment and presence of psychopathology at a premorbid level that determines resilience in this group. Coping with loss of a family member may not affect resilience if all other variables are the same. ${ }^{11}$

It is important to deviate here from resilience of those that undergo a trauma and mention that resilience is equally important for workers involved in disaster rescue and recovery operations. Even seasoned or trained disaster workers may experience uneasiness and stress in the situation they are facing. Resilience development is an important component of occupational safety and health and must be preplanned in disasters to promote worker recovery from the trauma as well. An important factor that affects disaster worker resilience is when they have to deal with dead bodies of adults and especially children. ${ }^{12}$ 
One of our own studies also demonstrated that it is associated with suicidal behaviour, severity of psychopathology and even to increased rates of re-hospitaliation. ${ }^{13}$

There may be underlying personal and cultural differences between workers and the community affected by disaster that may further impede efficiency of disaster relief operations. Disaster and essential service workers need to be monitored for stress management and resiliency development. Leadership and management training is a must for these workers. This also serves to maintain the continuity of rescue work while promoting organizational resilience in the disaster setting. Worker resilience when affected shall slow rescue work and shall in turn affect the resilience of those involved in the trauma along with community resilience as a whole. ${ }^{14}$

Resilience is thus a construct that determines the response of human beings and communities to natural disasters and their return to normalcy from the same. Most research has focused on the neurobiological, psychological and social factors that affect resilience. Resilience in normal individual unaffected by trauma is an understudied area. It is important that as societies develop, we must develop resilience building programmes that enhance the baseline resilience of a community and nation even in the absence of trauma or disaster. ${ }^{15}$ This shall help build a resilient response when disaster actually strikes the community. Interventions in community and individual settings need to be tailor made to enhance resilience and recovery. Natural disasters as a result of ecological changes are imminent and will occur. We need a resilient society that shall meet every challenge head on and recover in the face of these disasters. Resilience shall not only enhance the psychological well being of individuals butshall indirectly improve physical health as well. The effects of resiliency are transgenerational and shall help build a better future for generations to come.

\section{REFERENCES}

1. Oxford English Dictionary. Oxford University Press ; 2010.
2. Shrivastava A, Desousa A. Resilience: A psychobiological construct for psychiatric disorders. Indian J Psychiatry 2016;58(1):38-43.

3. Boon HJ, Cottrell A, King D, Stevenson RB, Millar J. Bronfenbrenner's bioecological theory for modelling community resilience to natural disasters. Nat Hazards 2012;60(2):381408.

4. Rutter M. Resilience as a dynamic concept. Dev Psychopathol 2012;24(2):335-44.

5. Russo SJ, Murrough JW, Han MH, Charney DS, Nestler EJ. Neurobiology of resilience. Nature Neurosci 2012;15(11):1475-84.

6. Southwick SM, Litz BT, Charney D, Friedman MJ. Resilience and mental health : challenges across the life span. Cambridge University Press : Cambridge, UK ; 2011.

7. Karatoreos IN, McEwen BS. Annual research review: The neurobiology and physiology of resilience and adaptation across the life course. J Child Psychol Psychiatry 2013;54(4):337-47.

8. Manyena SB. Disaster resilience: A question of 'multiple faces' and 'multiple spaces'?. Int J Disaster Risk Reduct 2014;8:1-9.

9. Poortinga $\mathrm{W}$. Community resilience and health: The role of bonding, bridging, and linking aspects of social capital. Health Place 2012;18(2):286-95.

10. Ungar M. Social ecologies and their contribution to resilience. Springer New York; 2012.

11. Lokhande C, Mohite N, De Sousa A, Shrivastava A, Shah N. Resilience in those who have lost a close family member in a natural disaster : a study from Uttarakhand, India. Indian J Ment Health (In Press). 
12. Zolli A, Healy AM. Resilience: Why things bounce back. Simon and Schuster; 2012.

13. Shrivastava A, De Sousa A, Shah N, Campbell R, Berlemont C. Resilience, Risk, Psychopathology and Psychiatric Hospitalization. Indian J Community Psychology 2014;10(1):1-6.

14. Flynn BW, McCarroll JE, Biggs QM. Stress and Resilience in Military Mortuary Workers: Care of the Dead From Battlefield to Home. Death Stud 2015;39(2):92-8.

15. Walker B, Salt D. Resilience practice: building capacity to absorb disturbance and maintain function. Island Press; 2012.

Acknowledgements - Nil

Conflict of Interest - Nil 